\title{
Effects of isometric handgrip training on blood pressure among hypertensive patients seen within public primary healthcare: a randomized controlled trial
}

\author{
Aline Cabral Palmeira', Breno Quintella Farah", Gustavo Oliveira da Silva"', Sérgio Rodrigues Moreira'v, Mauro Virgílio Gomes \\ de Barros", Marilia de Almeida Correiav", Gabriel Grizzo Cucatov", Raphael Mendes Ritti-Dias"vil
}

Primary healthcare units within the Family Health Program, Petrolina (PE), Brazil

'MSc. Professor, Physiotherapy and Nursing Departments, Faculdade São Francisco de Juazeiro (FASJ), Juazeiro (BA), Brazil. (D) https://orcid.org/0000-0002-6515-0523

"PhD. Professor, Physical Education Department, Universidade Federal Rural de Pernambuco, Recife (PE), Brazil; Associate Researcher, Postgraduate Program on Physical Education, Universidade Federal do Pernambuco (UFPE), Recife (PE), Brazil.

(D) https://orcid.org/0000-0003-2286-5892

"'MSc. Doctoral Student, Postgraduate Program on Rehabilitation Sciences, Universidade Nove de Julho (UNINOVE), São Paulo (SP), Brazil.

(ID https://orcid.org/0000-0001-6341-345X

IVhD. Professor, Postgraduate Program on Physical Education, Universidade Federal do Vale do São Francisco (UNIVASF), Petrolina (PE), Brazil. (iD) https://orcid.org/0000-0002-3068-5093

vPhD. Professor, Postgraduate Program on Physical Education, Universidade de Pernambuco (UPE), Recife (PE), Brazil. (D) https://orcid.org/0000-0003-3165-0965

viphD. Professor, Postgraduate Program on Medicine, Universidade Nove de Julho (UNINOVE), São Paulo (SP), Brazil.

(D) https://orcid.org/0000-0002-8983-3433

vilPhD. Professor, Department of Sport, Exercise and Rehabilitation, Northumbria University, Newcastle upon Tyne, United Kingdom. (D) https://orcid.org/0000-0002-2060-8852

VIIIPhD. Professor, Postgraduate Program on Rehabilitation Sciences, Universidade Nove de Julho (UNINOVE), São Paulo (SP), Brazil. (D) https://orcid.org/0000-0001-7883-6746

KEYWORDS (MeSH terms):

Hypertension.

Resistance training.

Primary health care

Blood pressure.

\section{AUTHORS' KEYWORDS:}

Cardiac autonomic modulation.

Strength training.

Primary care.

Isometric.

\begin{abstract}
BACKGROUND: Meta-analyses have demonstrated that isometric handgrip training $(\mathrm{IHT})$ decreases blood pressure in hypertensive individuals. Nonetheless, most studies were conducted in laboratory settings and its effects in real-world settings remain unclear.

OBJECTIVE: To analyze the effects of IHT on office and ambulatory blood pressure in hypertensive patients attended within primary healthcare.

DESIGN AND SETTING: Randomized controlled trial conducted in primary healthcare units within the Family Health Program, Petrolina, Pernambuco, Brazil.

METHODS: 63 hypertensive patients (30-79 years old; 70\% female) were randomly allocated into IHT or control groups. IHT was performed three times per week ( $4 \times 2$ minutes at $30 \%$ of maximal voluntary contraction, one-minute rest between bouts, alternating the hands). Before and after the 12-week training period, office and ambulatory blood pressure and heart rate variability were obtained. The significance level was set at $\mathrm{P}<0.05$ (two-tailed testing) for all analyses.

RESULTS: IHT significantly decreased office systolic blood pressure (IHT: $129 \pm 4$ versus $121 \pm 3 \mathrm{mmHg}$, P $<0.05$; control: $126 \pm 4$ versus $126 \pm 3 \mathrm{mmHg}, \mathrm{P}>0.05)$, whereas there was no effect on diastolic blood pressure (IHT: $83 \pm 3$ versus $79 \pm 2 \mathrm{mmHg}, P>0.05$; control: $81 \pm 3$ versus $77 \pm 3 \mathrm{mmHg}, \mathrm{P}>0.05$ ). Heart rate variability and ambulatory blood pressure were not altered by the interventions ( $P>0.05$ for all). CONCLUSION: $I H T$ reduced office systolic blood pressure in hypertensive patients attended within primary care. However, there were effects regarding diastolic blood pressure, ambulatory blood pressure or heart rate variability.
\end{abstract}

CLINICALTRIALS.GOV IDENTIFIER: NCT03216317.

\section{INTRODUCTION}

Hypertension impacts over one billion people worldwide and is the main risk factor for heart and cerebrovascular diseases, accounting for $13 \%$ of global deaths. ${ }^{1-3}$ The therapeutic approach for hypertensive patients includes drug therapy and lifestyle changes in association with drug therapy, with the aim of reducing blood pressure (BP) to the target normal range $(<130 / 80 \mathrm{mmHg})^{2}$

Previous meta-analyses have shown that isometric handgrip training (IHT) decreases office BP in hypertensive patients by more than $5 \mathrm{mmHg}$ after a few weeks. ${ }^{4-9}$ The American College of Cardiology and the American Heart Association have recently recommended IHT as a potential alternative strategy for lowering BP, but with a low level of evidence. ${ }^{10}$

From a clinical point of view, reductions in BP are relevant when this impacts on BP levels during a major part of the time. Interestingly, the effects of IHT on ambulatory BP, which is more related to cardiovascular events than office BP, have not been demonstrated. In fact, in three previous studies, despite significant reductions in office BP, no effects on ambulatory BP were shown among hypertensive individuals after IHT, thus suggesting that there was a need for further studies. ${ }^{11-13}$

The benefits of IHT comprise its ease of application and the short time needed for doing the exercise. Therefore, it is ideal for application within primary care, in non-laboratory settings. However, all clinical trials studies analyzing the effects of IHT on BP were conducted either in 
laboratory ${ }^{14}$ or in home settings. ${ }^{11,15}$ The potential effectiveness of this type of training at primary healthcare units is therefore unknown. Primary healthcare is the first point of contact that people have with the healthcare system when they have a health problem. The healthcare services provided within primary care include treatment of health conditions and support for managing long-term healthcare, including chronic conditions such as hypertension, at lower cost than in hospital settings.

\section{OBJECTIVE}

In this study, we analyzed the effects of IHT on office and ambulatory BP in hypertensive patients attended at a primary healthcare unit. Our hypothesis was that IHT would reduce BP similarly in non-laboratory settings.

\section{METHODS}

\section{Experimental approach to the problem}

A randomized controlled trial was used to investigate the effects of IHT on office and ambulatory BP among hypertensive patients attended at a primary healthcare unit. Medicated hypertensive patients were randomly assigned to either the IHT group or the control group. Ambulatory BP, office BP and heart rate variability parameters were measured before and after the 12-week intervention period by researchers blinded to the group allocations.

\section{Trial design}

This randomized controlled trial followed the Consolidated Standards of Reporting Trials (CONSORT) and was registered in the www.clinicaltrials.gov database under the registration number NCT03216317 and formed part of the ISOPRESS network. ${ }^{16,17}$ The study methods were approved by the Institutional Review Board of Universidade Federal do Vale do São Francisco (protocol number: 61442216.5.0000.5196; approval date: May 16, 2017) in conformity with the national research ethics system guidelines and with the Helsinki Declaration of 1975 (revised in 1983). Before participation, subjects provided written informed consent. ${ }^{18}$

\section{Subjects}

We invited medicated hypertensive patients at primary care units within the Family Health Program in the city of Petrolina, state of Pernambuco, northeastern Brazil, to participate in this study. These primary care units form part of the Brazilian public healthcare system, which serves the population in places near patients' homes. The eligibility criteria for the study were that the subjects needed to: i) be using anti-hypertensive medications; ii) be over the age of 18 years old; iii) have no presence of diabetes or cardiovascular disease (other than hypertension); iv) have no limitations on undergoing isometric handgrip training; and v) not be engaged in any systematic exercise programs assessed through the International Physical Activity Questionnaire. The exclusion criteria were any of the following situations: (a) changes to the type or dose of blood pressure control medicine; (b) engaging in another exercise program; or (c) taking part in less than $80 \%$ of the isometric handgrip training sessions.

\section{Randomization and allocation}

The participants were block-randomized using a random number table (using the website https://www.randomizer.org), with stratification according to sex and baseline office systolic BP (done by a researcher who did not participate in the subject recruitment or data collection), into two groups: IHT group and control group. The allocation information was concealed from the researchers performing the measurements.

\section{Interventions}

The patients allocated to the IHT group trained three times per week, for a total of 12 weeks, in healthcare units that form part of the Family Health Program. Each session was composed of four sets of two-minute isometric contractions (alternating the hands), done through a handgrip dynamometer (Zona Health, Boise, Idaho, United States) at 30\% of each patient's maximal voluntary contraction, which was established at the start of each session via the handgrip dynamometer. The Zona Plus dynamometer was developed specifically for isometric handgrip training. The screen in the device provides instantaneous feedback of the amount of force and indicates whether the amount of force applied is sufficient for the intensity selected. In addition, the device has a timer that provides information regarding the duration of the exercise and the rest intervals. Patients allocated to the control group were encouraged to increase their level of physical activity, but with no particular guidance on physical activity.

\section{Measurements}

Cardiovascular variables were measured at the baseline and at a follow-up (12 weeks later). The participants received the following instructions for what they should do before the cardiovascular evaluations: (a) have a light meal prior to arrival at the laboratory; (b) refrain from moderate-to-vigorous physical activity for at least $24 \mathrm{~h}$ before to the visit; and (c) refrain from smoking or alcohol or caffeine consumption for at least $12 \mathrm{~h}$. Researchers who were blinded to the group allocations collected the data. The post-intervention evaluation was performed at least 72 hours after the last exercise session.

Office BP: The office BP was measured through the Omron HEM 742 device (Omron Healthcare, Kyoto, Japan). After 10 minutes of supine rest, at least three consecutive measurements with 
one-minute intervals between them were assessed. The measurements were made on the right arm, with an appropriate cuff size for the arm circumference. ${ }^{19}$ The intraclass correlation coefficient for systolic BP was 0.85 , and for diastolic BP it was $0.92 .{ }^{20}$

Ambulatory BP: The ambulatory BP was obtained through an oscillometric device (Dyna-MAPA, Cardios, Brazil) that had previously been set up for performing BP assessments every 15 minutes during the daytime period and every 30 minutes during the nighttime, based on previously reported procedures. ${ }^{21}$ Also, patients were counseled to report crucial everyday activities, such as meals, movement from one place to another and medications.

Heart rate variability: The heart rate variability was evaluated from the RR intervals, measured through a heart rate monitor (Polar V800, Polar Electro, Kempele, Finland) in the supine position for 10 minutes. At least five minutes of stationary R-R interval data were analyzed. All analyses were carried out by a single experienced evaluator who was blind to the group allocations. The intraclass correlation coefficient for this evaluator spanned from 0.990 to $0.993 .^{22}$ All heart rate variability analysis procedures followed previously described guidelines. ${ }^{23}$ The Kubios HRV software (Biosignal Analysis and Medical Imaging Group, Joensuu, Finland) was used for the analysis. The time (standard deviation of all RR intervals [SDNN], root mean square of the squared differences between adjacent normal RR intervals [RMSSD] and percentage of adjacent intervals over $50 \mathrm{~ms}$ [PNN50]) and frequency (low frequency component, high frequency component and sympathovagal balance) domain variables were obtained.

\section{Statistical analyses}

To determine the sample size, we used previously demonstrated data on the mean reduction and standard deviation (SD) of office systolic BP following IHT. ${ }^{24}$ Given an expected reduction of $6.0 \pm 4.6 \mathrm{mmHg}$ and $\alpha$ of 0.05 and $\beta$ of 0.20 , an estimated sample size of 28 participants (14 per group) was deemed sufficient.

Normality and homogeneity of variances were verified by means of the Shapiro-Wilk test and the Levene test, respectively. Clinical characteristics were compared between the groups using the $t$ test, chi-square test and Fisher test. To analyze the effects of isometric handgrip training on $\mathrm{BP}$, generalized estimating equations were used, along with post-hoc pairwise comparison using the Bonferroni correction for multiple comparisons. Effect size (ES) was used to stipulate the magnitude of differences in the same group. Intention-to-treat analysis was used to estimate overall effects, among all the randomized patients while ignoring noncompliance and dropouts, and the data were imputed with linear regression weighted according to group. The significance level was set at $\mathrm{P}<0.05$ (two-tailed testing) for all analyses. The data were presented as means and standard errors or as $95 \%$ confidence intervals. Categorical variables were summarized as relative frequencies.

\section{RESULTS}

The recruitment and intervention periods encompassed July 2017 July to July 2018. The study flowchart is shown in Figure 1. The groups were similar at the baseline (Table 1).

The dropout rates were $51.6 \%$ in the isometric handgrip training group and $53.1 \%$ in the control group. Through comparing the characteristics of the patients who were included and the dropouts in the isometric handgrip training group (Table 2), only a difference in calcium channel blocker use could be seen $(P<0.05)$. One 61-year-old woman in the isometric handgrip training dropped out due to joint pain. Adherence in the IHT group was $84.6 \%$ ( $95 \%$ confidence interval, CI: $82.2 \%$ to $87.1 \%$ ).

Figure 2 and Table 3 present the effects of IHT on office BP and heart rate variability parameters, respectively. A group-time (GxT) interaction was observed for office systolic BP (power $=0.83$ ), which indicated that only the group that performed isometric handgrip training presented reductions in office systolic BP (IHT: $129 \pm 4$ versus $121 \pm 3 \mathrm{mmHg}$; and control: $126 \pm 4$ versus $126 \pm 3 \mathrm{mmHg}$; $\mathrm{P}<0.05)$. No GxT interaction was observed in relation to office diastolic BP (IHT: $83 \pm 3$ versus $79 \pm 2 \mathrm{mmHg}$; and control: $81 \pm 3$ versus $77 \pm 3 \mathrm{mmHg}$; $>0.05)$ (power $=0.52$ ) and heart rate variability parameters $(\mathrm{P}>0.05$ for all).

Figure 3 presents the effects of IHT on ambulatory BP. No group-time interaction ( $\mathrm{P}>0.05$ for all) was observed for $\mathrm{BP}$, overall over a 24 -hour period (systolic BP: IHT 119.2 \pm 3.3 versus $119.2 \pm 3.0 \mathrm{mmHg}, \mathrm{ES}=0.01$; control $116.9 \pm 2.2$ versus $118.6 \pm$ $2.4 \mathrm{mmHg}, \mathrm{ES}=0.18$, power $=0.54$; diastolic BP: IHT $80.5 \pm 3.0$ versus $78.1 \pm 2.4 \mathrm{mmHg}$, $\mathrm{ES}=0.27$; control $77.5 \pm 2.3$ versus 77.7 $\pm 2.2 \mathrm{mmHg}, \mathrm{ES}=0.02$, power $=0.69$ ); or while the subjects were awake (systolic BP: IHT $120.7 \pm 3.3$ versus $120.3 \pm 2.9 \mathrm{mmHg}$, ES $=0.03$; control $118.4 \pm 2.2$ versus. $120.1 \pm 2.3 \mathrm{mmHg}, \mathrm{ES}=0.18$; diastolic BP: IHT $82.0 \pm 2.9$ versus $79.3 \pm 2.5 \mathrm{mmHg}$, ES = 0.27; control $79.0 \pm 2.4$ versus $79.5 \pm 2.3 \mathrm{mmHg}$, ES $=0.05$ ) or asleep (systolic BP: IHT 113.1 \pm 3.7 versus $113.8 \pm 2.8 \mathrm{mmHg}, \mathrm{ES}=0.06$; control $110.0 \pm 2.1$ versus $111.7 \pm 2.7 \mathrm{mmHg}, \mathrm{ES}=0.17$; diastolic BP: IHT $73.3 \pm 3.6$ versus $72.5 \pm 2.4 \mathrm{mmHg}$, ES = 0.07; control $69.0 \pm$ 2.1 versus $70.8 \pm 2.3 \mathrm{mmHg}, \mathrm{ES}=0.20$ ) (Figure 3 ).

The intent-to-treat analysis did not reveal any significant effect from the IHT program on any of the outcome variables measured (data not shown).

\section{DISCUSSION}

The main results of this study in a primary healthcare unit were the following: (i) IHT reduced office systolic BP among medicated hypertensive individuals; (ii) no effects were observed in relation to office diastolic $\mathrm{BP}$, heart rate variability or ambulatory BP in medicated hypertensive patients.

The main novelty of this study was that the IHT program was conducted in a primary healthcare unit, which is a real-world setting 
for supervised training. We demonstrated that there was a reduction in office systolic BP in medicated hypertensive individuals, which corroborates previous studies conducted in laboratory or home settings. ${ }^{11,14,15}$ The magnitude of the reduction in office systolic BP was approximately $8 \mathrm{mmHg}$, which was similar to findings from previous clinical trial studies conducted in laboratory or home settings. ${ }^{8,25}$ Moreover, the analysis on individual responses indicated that $63 \%$ of the patients showed reductions in systolic BP of more than $5 \mathrm{mmHg}$, which may represent a reduction of at least $7 \%$ in the risks of stroke, coronary disease and death. ${ }^{26}$ Thus, IHT may be incorporated as alternative strategy for controlling office systolic BP in medicated hypertensive individuals who are treated in a primary care unit.

On the other hand, 12 weeks of IHT performed in a primary healthcare unit did not change office diastolic BP in these medicated hypertensive individuals. Although this result contrasts with the findings from some studies, there are other studies that also reported that there was no reduction in diastolic BP after IHT, among hypertensive patients. ${ }^{4-7}$ After six weeks of IHT in a laboratory setting, Peters et al. did not observe any reduction in office diastolic BP, although they observed a reduction in office systolic BP. ${ }^{27}$ Similarly, Taylor et al. demonstrated that there was a decrease in office systolic BP, but not in diastolic BP, after 10 weeks in a laboratory setting. ${ }^{28}$ Lastly, after 12 weeks of IHT in a laboratory or home setting, Gordon et al. did not find any reduction in diastolic BP. ${ }^{15}$

It is not clear why office systolic BP, but not diastolic BP, was found to have decreased after the 12-week training period. One possible explanation is that the patients included in the present study presented well-controlled values for diastolic BP in the pre-intervention period (all $<90 \mathrm{mmHg}$ ) and, as such, may have had a lower capacity for BP reduction through IHT. In fact, a previous study reported that individuals with higher pre-training resting BP had a greater post-training hypotensive response. ${ }^{29}$

In the present study, 12 weeks of IHT in hypertensive individuals did not have the capacity to promote improvement in cardiac autonomic modulation to the heart. Farah et al. did not find any improvements after 12 weeks of supervised or home-based isometric handgrip training in hypertensive individuals who were using medications. Similarly, Stiller-Moldovan et al. did not find any changes in cardiac autonomic modulation after 8 weeks of isometric handgrip training in hypertensive patients. ${ }^{11,13}$ In contrast, Taylor et al. found improvements in high-frequency spectral power among uncontrolled hypertensive individuals after supervised isometric handgrip training. Interestingly, in Taylor's study, the baseline BP values were higher than those of the present study (156 versus $129 \mathrm{mmHg}$ ). This indicates that isometric handgrip training might lead to improvements in autonomic cardiac modulation in individuals with uncontrolled $\mathrm{BP}^{28}$ Therefore, it

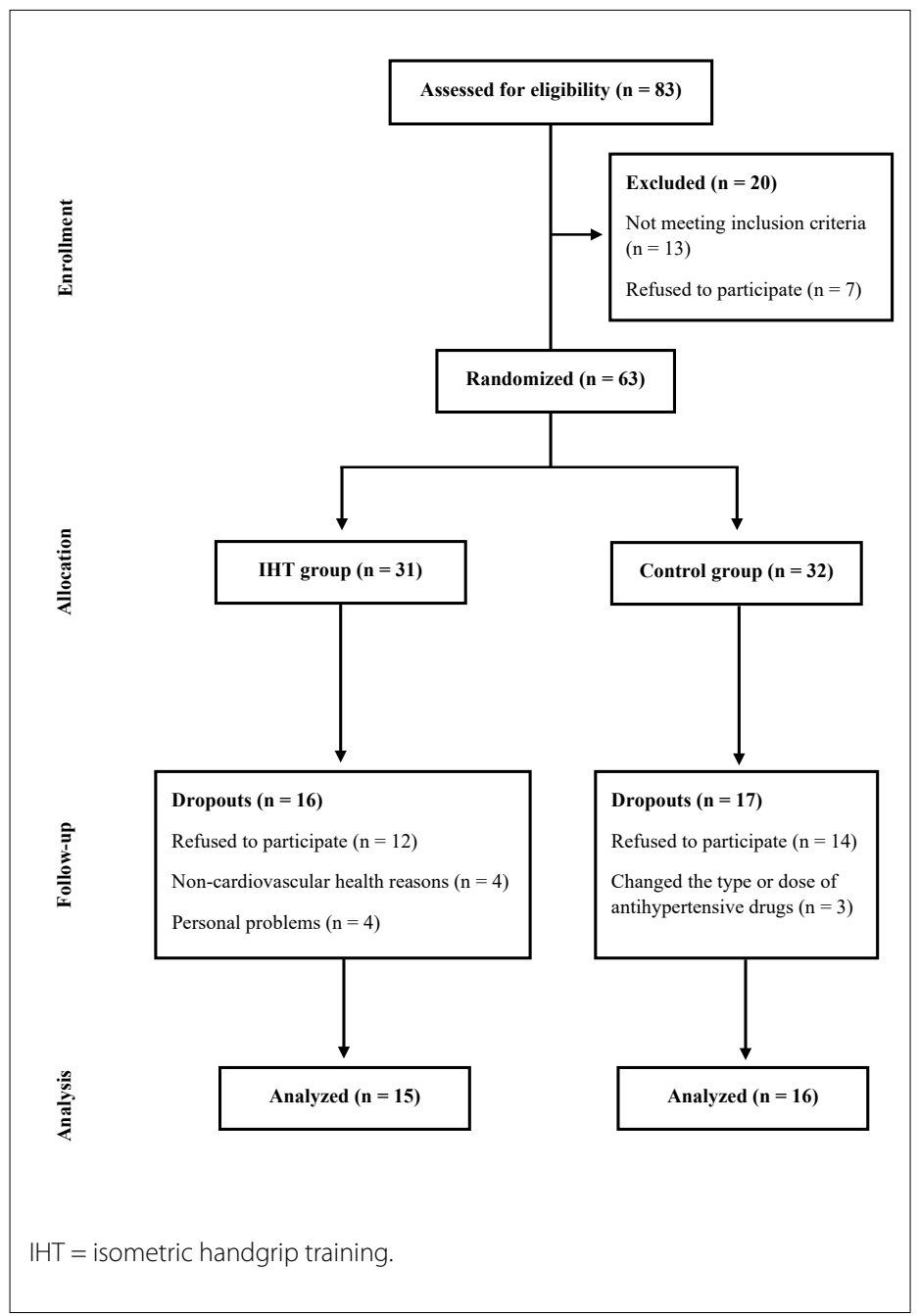

Figure 1. Flowchart of study.

is possible that other mechanisms are involved in the reduction of BP after IHT. ${ }^{30}$

Recently, our group demonstrated ${ }^{31}$ that a reduction in arterial stiffness occurs in hypertensive individuals who are responsive to isometric handgrip training. In addition, Peters et al. showed that there was enhancement of oxidative stress after six weeks of training and McGowan et al. observed improvement in endothelial function after eight weeks of IHT. 27,31,32

Ambulatory BP has been considered more important than office BP, in terms of clinical perspective, since it presents better prediction of target organ damage and cardiovascular mortality. ${ }^{33}$ Our results indicated that there was no reduction in any of the ambulatory BP measurements after 12 weeks of IHT performed in a primary healthcare unit and are in agreement with previous studies. ${ }^{11-13}$ A study conducted by Stiller-Moldovan et al. did not observe any reduction in ambulatory BP after eight weeks of isometric exercise training performed at $30 \%$ of maximal voluntary 
Table 1. General characteristics of experimental groups at baseline

\begin{tabular}{lccc} 
Variables & IHT & $\begin{array}{c}\text { Control } \\
\text { group }\end{array}$ & P \\
\hline Age (years) & $54.3 \pm 3.7$ & $52.7 \pm 2.6$ & 0.743 \\
\hline Weight $(\mathrm{kg})$ & $74.1 \pm 3.2$ & $80.1 \pm 4.9$ & 0.319 \\
\hline Body mass index $\left(\mathrm{kg} / \mathrm{m}^{2}\right)$ & $29.4 \pm 1.1$ & $31.6 \pm 1.5$ & 0.247 \\
\hline Office systolic BP $(\mathrm{mmHg})$ & $129 \pm 4$ & $126 \pm 4$ & 0.241 \\
\hline Office diastolic BP $(\mathrm{mmHg})$ & $83 \pm 3$ & $82 \pm 3$ & 0.632 \\
\hline Walking (minutes/week) & $122 \pm 25$ & $73 \pm 17$ & 0.123 \\
Moderate physical activity & $135 \pm 35$ & $64 \pm 26$ & 0.116 \\
(minutes/week) & 27 & 31 & 0.909 \\
Sex (\% men) & 18.8 & 0 & 0.103 \\
Current smoker (\%) & 7 & 6 & 0.898 \\
\hline Calcium channel blocker (\%) & 73 & 56 & 0.290 \\
\hline Diuretic (\%) & 20 & 11 & 0.478 \\
\hline B-blocker (\%) & 20 & 17 & 0.805 \\
\hline ACE inhibitor (\%) & 67 & 78 & 0.475
\end{tabular}

Values that are not percentages are presented as mean \pm standard error. IHT $=$ isometric handgrip training; $\mathrm{BP}=$ blood pressure.
Table 2. Comparison of the characteristics of the patients who were included and who were dropouts in this study

\begin{tabular}{lccc} 
Variables & $\begin{array}{c}\text { Included } \\
\mathbf{n}=\mathbf{3 1}\end{array}$ & $\begin{array}{c}\text { Dropout } \\
\mathbf{n}=\mathbf{3 3}\end{array}$ & $\mathbf{P}$ \\
\hline Intervention group (\%) & 45.7 & 53.3 & 0.540 \\
\hline Age (years) & $53.6 \pm 2.2$ & $55.6 \pm 1.8$ & 0.417 \\
\hline Weight (kg) & $75.6 \pm 2.6$ & $75.1 \pm 2.8$ & 0.890 \\
\hline Body mass index (kg/m ${ }^{2}$ ) & $30.1 \pm 0.9$ & $29.1 \pm 0.9$ & 0.431 \\
\hline Office systolic BP $(\mathrm{mmHg})$ & $126 \pm 3$ & $128 \pm 2$ & 0.518 \\
\hline Office diastolic BP $(\mathrm{mmHg})$ & $81 \pm 2$ & $79 \pm 2$ & 0.401 \\
\hline Walking (minutes/week) & $97 \pm 15$ & $157 \pm 66$ & 0.366 \\
\hline Moderate physical activity & $99 \pm 22$ & $99 \pm 22$ & 0.165 \\
(minutes/week) & 27 & 50 & 0.183 \\
\hline Sex (\% men) & 3 & 33 & 0.002 \\
Calcium channel blocker (\%) & 64 & 40 & 0.079 \\
\hline Diuretic (\%) & 15 & 27 & 0.259 \\
\hline B-blocker (\%) & 18 & 20 & 0.854 \\
\hline ACE inhibitor (\%) & 73 & 60 & 0.285
\end{tabular}

Values that are not percentages are presented as mean \pm standard error. $\mathrm{HT}=$ isometric handgrip training; $\mathrm{BP}=$ blood pressure.

A

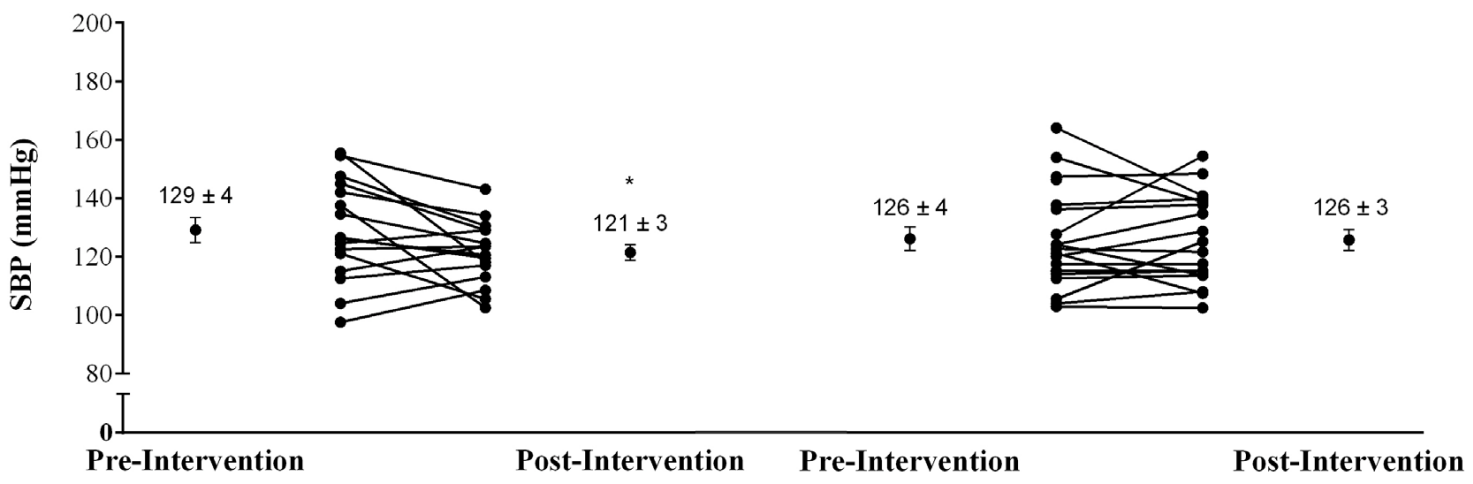

B
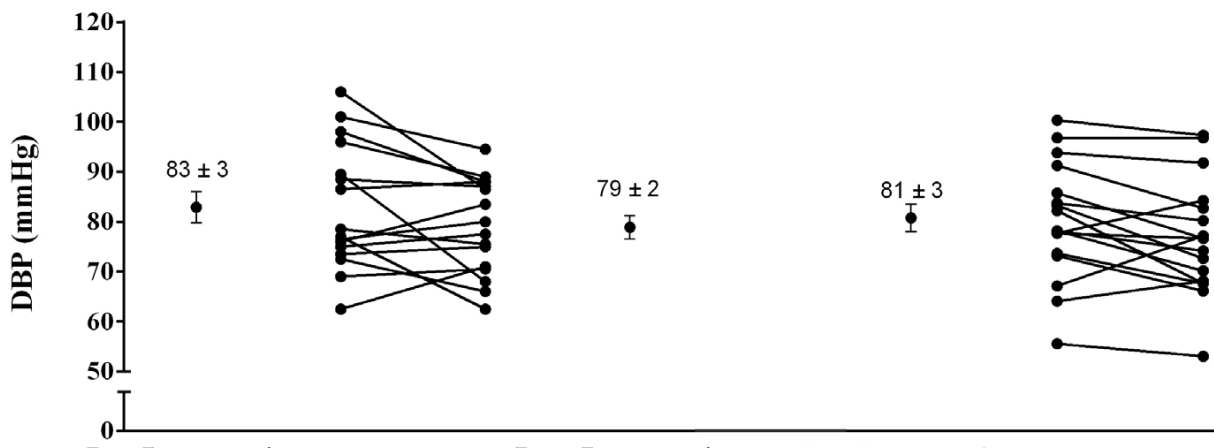

$77 \pm 3$
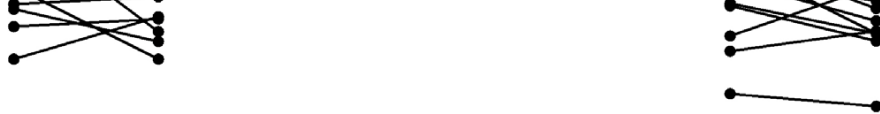

$\Phi$

Pre-Intervention

Post-Intervention

Pre-Intervention

Post-Intervention

Figure 2. Effects of isometric handgrip training on office blood pressure. $A$ - Systolic blood pressure (SBP) (P-values: group $=0.900$; time $=0.088 ; G \times T=0.049) ; B$ - Diastolic blood pressure (DBP) (P-values: group $=0.531 ;$ time $=0.003 ; G x T=0.933)$. ${ }^{*}$ Significant difference from Pre $(P<0.05)$. IHT, isometric handgrip training; $C G$, control group; $G \times T$, group-time interaction. 
Table 3. Effects of isometric handgrip training on heart rate variability parameters in hypertensive individuals

\begin{tabular}{|c|c|c|c|c|c|}
\hline \multirow{2}{*}{ Variables } & \multicolumn{2}{|c|}{ IHT } & \multicolumn{2}{|c|}{ Control } & \multirow{2}{*}{$\mathbf{P}$} \\
\hline & Pre-Intervention & Post-Intervention & Pre-Intervention & Post-Intervention & \\
\hline RR interval (ms) & $819 \pm 32$ & $854 \pm 23$ & $831 \pm 22$ & $829 \pm 25$ & 0.166 \\
\hline SDNN (ms) & $31.6 \pm 4.5$ & $32.4 \pm 5.6$ & $34.3 \pm 2.9$ & $34.7 \pm 3.3$ & 0.928 \\
\hline RMSSD (ms) & $29.1 \pm 7.5$ & $32.3 \pm 8.8$ & $25.1 \pm 2.9$ & $27.0 \pm 3.4$ & 0.923 \\
\hline PNN50 (\%) & $9.2 \pm 4.6$ & $11.8 \pm 4.7$ & $7.4 \pm 2.3$ & $8.5 \pm 2.7$ & 0.837 \\
\hline $\mathrm{LF}(\mathrm{nu})$ & $47.9 \pm 4.7$ & $50.0 \pm 5.6$ & $57.3 \pm 5.1$ & $56.5 \pm 4.9$ & 0.595 \\
\hline$H F(n u)$ & $51.5 \pm 4.7$ & $49.8 \pm 5.6$ & $42.5 \pm 5.1$ & $43.3 \pm 4.9$ & 0.664 \\
\hline LF/HF & $1.17 \pm 0.18$ & $1.44 \pm 0.311$ & $2.07 \pm 0.39$ & $2.32 \pm 0.76$ & 0.785 \\
\hline
\end{tabular}

Values are presented as mean \pm standard error. $I H T=$ isometric handgrip training; HF = High frequency; LF = Low frequency; SDNN = standard deviation of all RR intervals; RMSSD = root mean square of the squared differences between adjacent normal RR intervals; PNN50 = percentage of adjacent intervals over 50 $\mathrm{ms} ; \mathrm{LF} / \mathrm{HF}=$ sympathovagal balance; $\mathrm{nu}=$ normalized units.

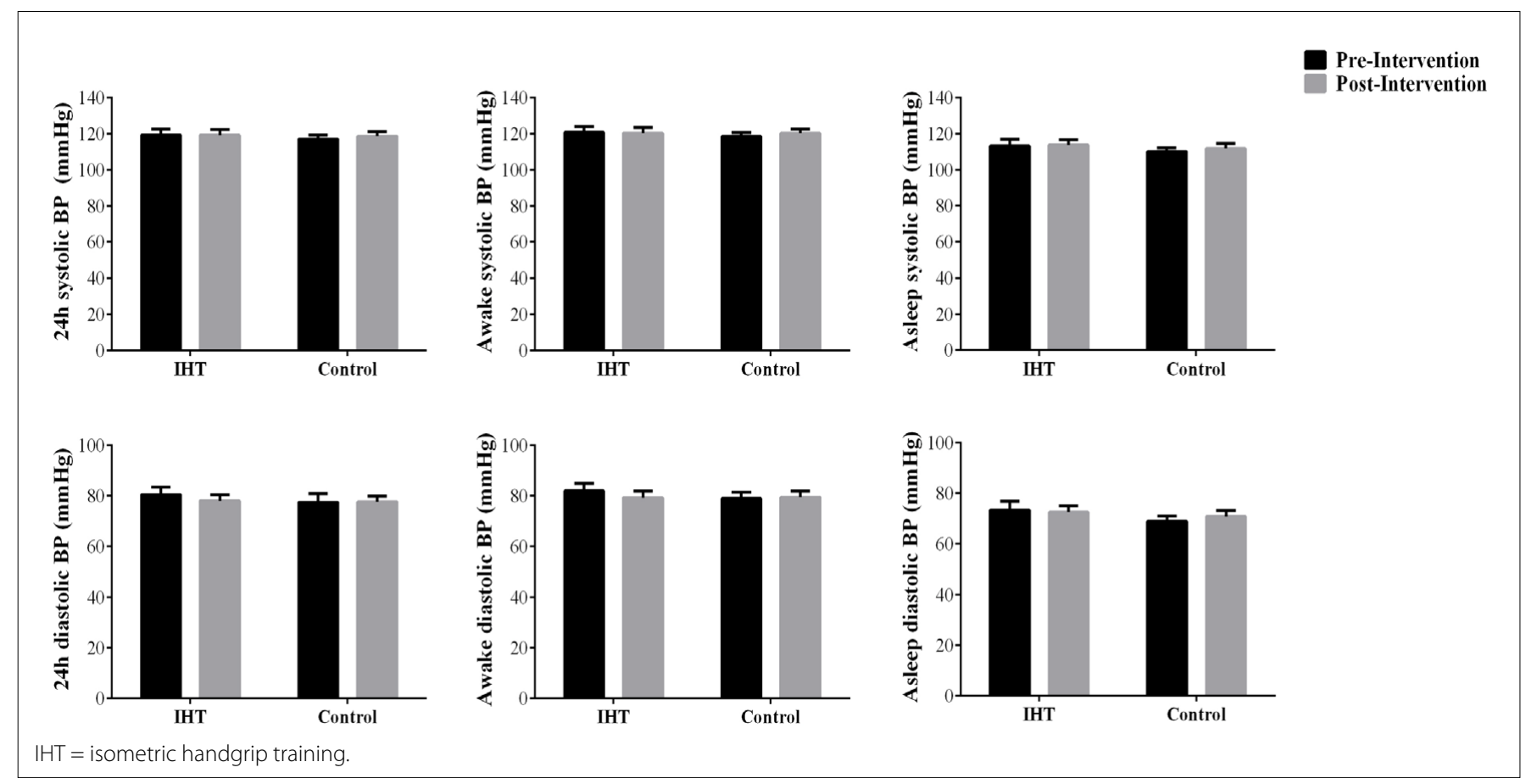

Figure 3. Effects of isometric handgrip training on ambulatory blood pressure.

contraction. ${ }^{13}$ Moreover, Pagonas et al. also showed that there was no reduction in ambulatory BP after 12 weeks of handgrip exercise training performed five times per week at $30 \%$ of maximal voluntary contraction, in a hypertensive population. ${ }^{12}$ Therefore, these results indicate that isometric handgrip training presents only a transient effect on BP that is only observed in office BP and is not prolonged during ambulatory activities.

The American Heart Association and American College of Cardiology have recommended isometric handgrip training as a potential alternative strategy for lowering BP in the hypertensive population. ${ }^{10}$ The benefits of this type of training comprise its ease of application and the short time that needs to be dedicated to implementing the exercise, such that it is ideal for application in primary care and in non-laboratory settings. In fact, three sessions per week and 12 minutes per session (i.e. 36 minutes per week) is less time than the current recommendations ${ }^{34,35}$ for physical exercise (150 minutes per week), which therefore enables avoidance of important barriers to physical activity practice among patients with cardiovascular diseases. ${ }^{36,37}$

In the present study, we demonstrated that isometric handgrip training reduces office systolic BP in medicated hypertensive patients who were attended in primary healthcare settings. However, we failed to show that this has any efficacy with regard to office diastolic BP, ambulatory BP or heart rate variability parameters. In addition, our dropout rate was higher than in previous studies conducted in laboratory or home settings, which suggests 
that caution is required in implementing isometric handgrip training in primary care settings.

The present study presents limitations that should be considered. The sample size did not allow for stratified analysis according to the medication used. This might have enabled comprehension of the mechanism(s) of BP lowering after isometric handgrip training. Generalizations of these findings to other populations (either those with advanced hypertension or other populations) must be made with care. The dropout rate in this study was higher than that we would have liked. It is not possible to assume that similar results would be observed among patients who dropped out of the program, and these data should be considered with caution. In addition, we did not do intention-to-treat analyses. Although without any statistically significant difference, the control group was heavier than the IHT group, and this needs to be taken into account. Lack of control regarding physical activity in both groups was also a limitation, although none of the patients engaged in any exercise programs. Lastly, other mechanisms for BP lowering after isometric handgrip training, such as baroreflex sensitivity, vascular measures or use of biomarkers, were not assessed. ${ }^{27,32,38}$

\section{CONCLUSION}

Isometric handgrip training performed in a primary care setting reduced office systolic BP in hypertensive patients, whereas no effects were observed in relation to office diastolic BP, ambulatory $\mathrm{BP}$ or heart rate variability.

\section{REFERENCES}

1. Kearney PM, Whelton M, Reynolds K, et al. Global burden of hypertension: analysis of worldwide data. Lancet. 2005;365(9455):217-23. PMID: 15652604; https://doi.org/10.1016/S0140-6736(05)17741-1.

2. Whelton PK, Carey RM, Aronow WS, et al. 2017 ACC/AHA/AAPA/ABC/ ACPM/AGS/APhA/ASH/ASPC/NMA/PCNA Guideline for the Prevention, Detection, Evaluation, and Management of High Blood Pressure in Adults: A Report of the American College of Cardiology/American Heart Association Task Force on Clinical Practice Guidelines. J Am Coll Cardiol. 2018;71(19):e127-e248. PMID: 29146535; https://doi.org/10.1016/j. jacc.2017.11.006. Erratum in: J Am Coll Cardiol. 2018;71(19):2275-9.

3. Lewington S, Clarke R, Qizilbash N, et al. Age-specific relevance of usual blood pressure to vascular mortality: a meta-analysis of individual data for one million adults in 61 prospective studies. Lancet. 2002;360(9349):1903-13. PMID: 12493255; https://doi.org/10.1016/ s0140-6736(02)11911-8. Erratum in: Lancet. 2003;361(9362):1060.

4. CornelissenVA, SmartNA. Exercise training for blood pressure: a systematic review and meta-analysis. J Am Heart Assoc. 2013;2(1):e004473. PMID: 23525435; https://doi.org/10.1161/JAHA.112.004473.

5. Carlson DJ, Dieberg G, Hess NC, Millar PJ, Smart NA. Isometric exercise training for blood pressure management: a systematic review and meta-analysis. Mayo Clin Proc. 2014;89(3):327-34. PMID: 24582191; https://doi.org/10.1016/j.mayocp.2013.10.030.

6. Inder JD, Carlson DJ, Dieberg G, et al. Isometric exercise training for blood pressure management: a systematic review and meta-analysis to optimize benefit. Hypertens Res. 2016;39(2):88-94. PMID: 26467494; https://doi.org/10.1038/hr.2015.111.

7. Jin YZ, Yan S, Yuan WX. Effect of isometric handgrip training on resting blood pressure in adults: a meta-analysis of randomized controlled trials. J Sports Med Phys Fitness. 2017;57(1-2):154-60. PMID: 26558836; https://doi.org/10.23736/S0022-4707.16.05887-4.

8. Bentley DC, Nguyen CH, Thomas SG. Resting blood pressure reductions following handgrip exercise training and the impact of age and sex: a systematic review and narrative synthesis. Syst Rev. 2018;7(1):229. PMID: 30541603; https://doi.org/10.1186/s13643-018-0876-5.

9. Smart NA, Way D, Carlson D, et al. Effects of isometric resistance training on resting blood pressure: individual participant data metaanalysis. J Hypertens. 2019;37(10):1927-38. PMID: 30889048; https:// doi.org/10.1097/HJH.0000000000002105.

10. Carey RM, Whelton PK; 2017 ACC/AHA Hypertension Guideline Writing Committee. Prevention, Detection, Evaluation, and Management of High Blood Pressure in Adults: Synopsis of the 2017 American College of Cardiology/American Heart Association Hypertension Guideline. Ann Intern Med. 2018;168(5):351-8.PMID:29357392; https://doi.org/10.7326/M17-3203.

11. Farah $B Q$, Rodrigues SLC, Silva GO, et al. Supervised, but Not HomeBased, Isometric Training Improves Brachial and Central Blood Pressure in Medicated Hypertensive Patients: A Randomized Controlled Trial. Front Physiol. 2018;9:961. PMID: 30083107; https://doi.org/10.3389/ fphys.2018.00961

12. Pagonas N, Vlatsas S, Bauer F, et al. Aerobic versus isometric handgrip exercise in hypertension: a randomized controlled trial. J Hypertens. 2017;35(11):2199-206. PMID: 28622156; https://doi.org/10.1097/ HJH.0000000000001445.

13. Stiller-Moldovan C, Kenno K, McGowan CL. Effects of isometric handgrip training on blood pressure (resting and $24 \mathrm{~h}$ ambulatory) and heart rate variability in medicated hypertensive patients. Blood Press Monit.2012;17(2):5561. PMID: 22322195; https://doi.org/10.1097/MBP.0b013e32835136fa.

14. Farah BQ, Germano-Soares AH, Rodrigues SLC, et al. Acute and Chronic Effects of Isometric Handgrip Exercise on Cardiovascular Variables in Hypertensive Patients: A Systematic Review. Sports (Basel). 2017;5(3):55. PMID: 29910415; https://doi.org/10.3390/sports5030055.

15. Gordon BDH, Thomas EV, Warren-Findlow J, et al. A comparison of blood pressure reductions following 12-weeks of isometric exercise training either in the laboratory or at home. J Am Soc Hypertens. 2018;12(11):798-808. PMID: 30342777; https://doi.org/10.1016/j.jash.2018.09.003.

16. Schulz KF, Altman DG, Moher D, et al. CONSORT 2010 Statement: updated guidelines for reporting parallel group randomised trials. BMC Med. 2010;8(18). https://doi.org/10.1186/1741-7015-8-18.

17. Farah $B Q$, Vianna $L C$, Rodrigues $S L C$, et al. Effects of isometric handgrip training in patients with cardiovascular disease: rationale and design 
of the ISOPRESS network. Motriz: Rev Educ Fís. 2017;23(4):e101719. http://dx.doi.org/10.1590/s1980-6574201700040011.

18. Harriss DJ, Macsween A,Atkinson G. Standards for Ethics in Sportand Exercise Science Research: 2018 Update. Int J Sports Med. 2017;38(14):1126-31. PMID: 29258155; https://doi.org/10.1055/s-0043-124001.

19. Malachias MV. 7th Brazilian Guideline of Arterial Hypertension: Presentation. Arq Bras Cardiol. 2016;107(3 Suppl 3):0. PMID: 27819379; https://doi.org/10.5935/abc.20160140.

20. Gerage AM, Benedetti TR, Farah BQ, et al. Sedentary Behavior and Light Physical Activity Are Associated with Brachial and Central Blood Pressure in Hypertensive Patients. PLoS One. 20150;10(12):e0146078. PMID: 26717310; https://doi.org/10.1371/journal.pone.0146078.

21. Parati G, Stergiou G, O'Brien E, et al. European Society of Hypertension practice guidelines for ambulatory blood pressure monitoring. J Hypertens. 2014;32(7):1359-66. PMID: 24886823; https://doi. org/10.1097/HJH.0000000000000221.

22. Farah BQ, Lima AH, Cavalcante BR, et al. Intra-individuals and interand intra-observer reliability of short-term heart rate variability in adolescents. Clin Physiol Funct Imaging. 2016;36(1):33-9. PMID: 25216444; https://doi.org/10.1111/cpf.12190.

23. Heart rate variability: standards of measurement, physiological interpretation and clinical use. Task Force of the European Society of Cardiology and the North American Society of Pacing and Electrophysiology. Circulation. 1996;93(5):1043-65. PMID: 8598068.

24. McGowan CL, Levy AS, McCartney N, MacDonald MJ. Isometric handgrip training does not improve flow-mediated dilation in subjects with normal blood pressure. Clin Sci (Lond). 2007;112(7):403-9. PMID: 17140398; https://doi.org/10.1042/CS20060195.

25. Millar PJ, McGowan CL, Cornelissen VA, Araujo CG, Swaine IL. Evidence for the role of isometric exercise training in reducing blood pressure: potential mechanisms and future directions. Sports Med. 2014;44(3):345-56. PMID: 24174307; https://doi.org/10.1007/ s40279-013-0118-x.

26. Whelton PK, He J, Appel LJ, et al. Primary prevention of hypertension: clinical and public health advisory from The National High Blood Pressure Education Program. JAMA. 2002;288(15):1882-8. PMID: 12377087; https://doi.org/10.1001/jama.288.15.1882.

27. Peters PG, Alessio HM, Hagerman AE, et al. Short-term isometric exercise reduces systolic blood pressure in hypertensive adults: possible role of reactive oxygen species. Int J Cardiol. 2006;1 10(2):199-205. PMID: 16239039; https://doi.org/10.1016/j.ijcard.2005.07.035.

28. Taylor AC, McCartney N, Kamath MV, Wiley RL. Isometric training lowers resting blood pressure and modulates autonomic control. Med Sci Sports Exerc. 2003;35(2):251-6. PMID: 12569213; https://doi. org/10.1249/01.MSS.0000048725.15026.B5.

29. Millar PJ, Bray SR, McGowan CL, MacDonald MJ, McCartney N. Effects of isometric handgrip training among people medicated for hypertension: a multilevel analysis. Blood Press Monit. 2007t;12(5):307-14. PMID: 17890969; https://doi.org/10.1097/MBP.0b013e3282cb05db.
30. Farah $B Q$, Christofaro DGD, Correia MA, et al. Effects of isometric handgrip training on cardiac autonomic profile: A systematic review and metaanalysis study. Clin Physiol Funct Imaging. 2020;40(3):141-7. PMID: 31971353; https://doi.org/10.1111/cpf.12619.

31. Cahu Rodrigues SL, Farah BQ, Silva G, et al. Vascular effects of isometric handgrip training in hypertensives. Clin Exp Hypertens. 2020;42(1):2430. PMID: 30626217; https://doi.org/10.1080/10641963.2018.1557683.

32. McGowan $C L$, Visocchi A, Faulkner M, et al. Isometric handgrip training improves local flow-mediated dilation in medicated hypertensives. Eur J Appl Physiol. 2007;99(3):227-34. PMID: 17106718; https://doi. org/10.1007/s00421-006-0337-z. Erratum in: Eur J Appl Physiol. 2008;103(2):251.

33. Salles GF, Cardoso CR, Muxfeldt ES. Prognostic influence of office and ambulatory blood pressures in resistant hypertension. Arch Intern Med. 2008;168(21):2340-6. PMID: 19029499; https://doi.org/10.1001/ archinte.168.21.2340.

34. Bull FC, Al-Ansari SS, Biddle S, et al. World Health Organization 2020 guidelines on physical activity and sedentary behaviour. Br J Sports Med. 2020;54(24):1451-62. PMID: 33239350; https://doi.org/10.1136/ bjsports-2020-102955.

35. Barroso WKS, Rodrigues CIS, Bortolotto LA, Mota-Gomes MA, Brandão AA, Feitosa ADdM, et al. Brazilian Guidelines of Hypertension - 2020. Arq Bras Cardiol. 2021 116(3): 516-658.

36. de Sousa ASA, Correia MA, Farah BQ, et al. Barriers and Levels of Physical Activity in Patients With Symptomatic Peripheral Artery Disease: Comparison Between Women and Men. J Aging Phys Act. 2019;27(5):719-24. PMID: 30747555; https://doi.org/10.1123/ japa.2018-0206.

37. Cavalcante $\mathrm{BR}$, Farah $\mathrm{BQ}$, dos A Barbosa JP, et al. Are the barriers for physical activity practice equal for all peripheral artery disease patients? Arch Phys Med Rehabil. 2015;96(2):248-52. PMID: 25281872; https:// doi.org/10.1016/j.apmr.2014.09.009.

38. Teixeira AL, Ritti-Dias R, Antonino D, et al. Sex Differences in Cardiac Baroreflex Sensitivity after Isometric Handgrip Exercise. Med Sci Sports Exerc. 2018;50(4):770-7. PMID: 29135601; https://doi.org/10.1249/ MSS.0000000000001487.

Authors' contributions: Palmeira AC: Conception and design, data collection and writing; Farah BQ: conception and design, statistical analysis and writing; Silva GO: statistical analysis and writing; Moreira SR: conception and design, data collection and writing; Barros MVG: conception and design, obtaining funding and critical review; Correia MA: conception and design, data collection and critical review; Cucato GG: conception and design and critical review; and Ritti-Dias RM: conception and design, obtaining funding and critical review. All authors approved the final version to be published and have agreed to be accountable for all aspects of the work and for ensuring that questions relating to the accuracy or integrity of any part of the work are appropriately investigated and resolved 
Sources of funding: RMRD and MVGB held research productivity

fellowships granted by Conselho Nacional de Desenvolvimento

Científico e Tecnológico (CNPq), grant number 310508/2017-7, and

Fundação de Amparo à Ciência e Tecnologia do Estado de Pernambuco

(FACEPE), grant number 1177-4.09/14. This study was also supported by

Coordenação de Aperfeiçoamento de Pessoal de Nível Superior (CAPES),

grant number 01.

Conflict of interest: The authors declare that they did not have any

conflict of interest

Date of first submission: December 28, 2020

Last received: March 23, 2021

Accepted: April 22, 2021

Address for correspondence:

Raphael Mendes Ritti-Dias

Programa de Pós-graduação em Ciência da Reabilitação, Universidade

Nove de Julho

R. Vergueiro, 235

São Paulo (SP) — Brasil

CEP 01504-000

Tel. (+55 19) 99940-6878

E-mail: raphaelritti@gmail.com 